\title{
EL LIBRO-ARTE/LIBRO DE ARTISTA EN SU DIMENSIÓN DIGITAL: EL E-LIBRO-ARTE Y EL HIPERLIBRO-ARTE
}

\author{
The book art/artist book in its digital dimension: \\ E-book art and hyperbook-art
}

\section{Bibiana Crespo-Martín}

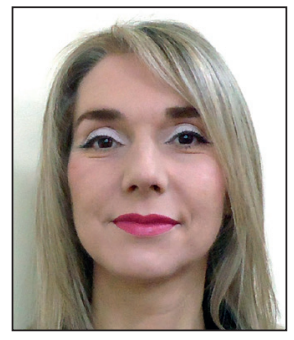

Bibiana Crespo-Martín es doctora en bellas artes por la Universitat de Barcelona (UB) y profesora en la Facultad de Bellas Artes de la misma institución. Profesora invitada en la University of California Berkeley (USA), la Universidad Nacional Autónoma de México (CD México) y la University of the West of England (Bristol, UK), entre otras. Miembro del grupo de investigación consolidado Poesia i Educació, sus investigaciones versan sobre el estudio de libros-arte/libros de artista cuyos resultados están publicados en libros, capítulos y artículos en revistas especializadas. http://orcid.org/0000-0003-2746-9944

Universitat de Barcelona, Facultat de Belles Arts Pau Gargallo, 4. 08028 Barcelona, España bbcrespo@ub.edu

\section{Resumen}

El presente contexto digital suministra un potencial a los creadores de libros-arte/libros de artista que ya están en efervescente producción realizando obras de arte innovadoras, dinámicas y fluidas, en y alrededor del libro. El marco en el que éste se desarrolla ha originado diversos posicionamientos del mismo que requieren ser analizados y sistematizados. Este artículo presenta el e-libro-arte (libro-arte electrónico) y el hiperlibro-arte como las dos taxonomías que abarca el libro-arte/libro de artista bajo parámetros de creación electrónica y en la Red. Se definen ambas acepciones y se estudian sus pertinentes propiedades y atributos conceptuales y estéticos, así como se da cuenta de ejemplos. Las reflexiones finales abren diversas líneas de debate que afloran ante este escenario digital como son el heterogéneo rol del creador y el espectador, la autoría de la obra, la transformación de la obra hacia un original múltiple, etc.

\section{Palabras clave}

Libro-arte; Libro-arte electrónico; Hiperlibro-arte; Libro-arte digital; Libro de artista; Hipertexto; Hipermedia; Multimedia.

\section{Abstract}

The current digital context holds potential for creators of books art/artist books to go beyond their already innovative, dynamic, and fluid works of art in and around the book. The framework for developing these works of art has led to diverse offerings that need to be analyzed and systematized. This article presents the e-book art (electronic book art) and hyperbookart as two taxonomies that the book art/artist book embraces under the parameters of electronic and internet creation. Both meanings are defined and their pertinent conceptual and aesthetic properties and attributes are studied. Examples are given. The final reflections open several lines of debate about this digital scene, including the heterogenous role of the creator and audience, the authorship of the work, and the transformation of the work towards a multiple original.

\section{Keywords}

Book art; Electronic book art; Hyperbook art; Digital book art; Artist book; Hypertext, Hypermedia; Multimedia.

Crespo-Martín, Bibiana (2016). "El libro-arte/libro de artista en su dimensión digital: el e-libro-arte y el hiperlibro-arte". El profesional de la información, v. 25, n. 5, pp. 822-830.

https://doi.org/10.3145/epi.2016.sep.13 


\section{El libro-arte/libro de artista y el contexto digital}

Desde finales del pasado siglo existe numerosa bibliografía especializada sobre el libro-arte y el libro de artista, el análisis de su clasificación taxonómica, sus cualidades, y sus propiedades formales y estéticas. Y aunque no son sinónimos, ni mucho menos lo mismo, suelen utilizarse como tal en el par libro-arte/libro de artista en numerosos ámbitos artísticos. Si bien el término libro-arte, por su concepción integradora de este género, abarca el tipo libro de artista (CrespoMartín, 2010, pp. 10-11), en este artículo se mantiene el binomio en el epígrafe a fin de armonizar la publicación con su atavismo. Por el enfoque y propósito propedéutico ${ }^{1}$ de este trabajo, entendemos por libro-arte aquellas creaciones artísticas que mantienen algún tipo de concomitancia con la idea de libro (Crespo-Martín, 2012, p. 2).

Pero es en pleno siglo XXI, y el escenario tecnológico que le acompaña, el que proporciona ahora una inédita dimensión al libro-arte. El arte contemporáneo y su alianza con las tecnologías digitales tiene a su servicio un sinfín de estrategias creativas que los artistas han abordado. En esta prolífica actualidad contamos ya con un acervo de libros-arte realizados con técnicas digitales que nos posicionan ante una necesaria reflexión y sistematización conceptual, procesual y estética del libro-arte/libro de artista en su magnitud digital. Este panorama digital del libro-arte presenta dos clasificaciones:

- e-libro-arte (libro-arte electrónico)

- hiperlibro-arte.

El libro-arte en el contexto digital presenta dos clasificaciones: el e-libro-arte (libro-arte electrónico) y el hiperlibro-arte

Uno de los motivos que ha revolucionado la creación en el libro digital es la gran cantidad de medios productivos, es decir, de software digital disponible para la realización y distribución de libros. Con ello han despertado un renovado interés las producciones en papel surgidas del deseo de desafiar u oponerse a las cada vez más corrientes publicaciones electrónicas.

"En torno al libro electrónico se desenvuelve una de las aporías más significativas de la sociedad digital: desde hace más de dos décadas, el libro en papel resiste con éxito el envite de su competidor digital, el libro electrónico" (García-Marco, 2008, p. 373).

Bajo este marco contextual surge con fuerza el consabido e-libro -libro electrónico-, y por extensión de su acepción podemos aducir al e-libro-arte. Éstos aportan significados adicionales en cuanto a la exposición de los libros-arte a una audiencia más amplia a través de la digitalización. Por otra parte, los hiperlibros-arte se fundamentan en la provisión de un espacio alternativo en la realización de libros-arte mediante el lenguaje propio de la tecnología digital caracterizado por ser un documento navegable. Mientras los primeros suponen casi el acto de traducción del objeto original a una forma digital sin apenas transgredir, a lo sumo fusionando, las propiedades inherentes a los libros-arte en su noción más convencional -como el pliego virtual de la paginación-, los segundos son una invitación creativa para trabajar exclusivamente con el medio digital y sus particularidades (Bodman; Sowden, 2010, p. 5).

El e-libro-arte se puede definir como aquel libro-arte servido en un soporte electrónico que precisa para su visualización de una pantalla textual, una pantalla gráfica, y/o unos dispositivos de emisión de audio, vídeo, etc., según el tipo de información que contenga. Algunos e-libros-arte necesitan de la mediación de un ordenador -si es que la información está digitalizada-, aunque puede que en otros no -si se trata de información analógica-. En este sentido, un e-libroarte puede tratarse de un libro-arte impreso que ha sido digitalizado y/o de un libro-arte digital concebido para poder ser impreso -aunque bien puede cumplir su cometido sin su expresa necesidad, además de la obviedad que supone que en el momento en que pasa a soporte papel, el libro deja de poseer atributos electrónicos-.

El e-libro-arte es un libro-arte servido en un soporte electrónico que precisa para su visualización de una pantalla textual, una pantalla gráfica, y/o unos dispositivos de emisión de audio, video, etc.

El soporte electrónico de un e-libro-arte dota de sistemas ampliados de exponer su contenido a un gran público mediante la digitalización. No obstante, aparte de esta particularidad, su estructura lineal de organización de contenidos y disposiciones secuenciales conlleva una funcionalidad similar a la del libro-arte impreso más tradicional. En términos formales, en la actualidad el e-libro-arte revolotea entre lo que el escritor y artista Radoslaw Nowakowski (2009) ha denominado el ppapel y el e-papel. Y así se pueden distinguir:

- e-libros-arte originalmente impresos que han sido digitalizados y ocasionalmente pueden imprimirse nuevamente;

- o en sentido inverso, e-libros-arte digitales creados para poder ser impresos.

No en vano es ante esta ecuación del e-libro-arte que Johanna Drucker señala muy acertadamente que:

"Las presentaciones electrónicas a menudo imitan los elementos más kitsch de la iconografía del libro, mientras que las características más novedosas de la funcionalidad electrónica parecen no haber encontrado su lugar en absoluto en la interfaz" (Drucker, 2003).

Y es que función no es lo mismo que característica formal, siendo este aspecto formal de lo electrónico donde parece residir la singularidad del e-libro-arte.

Sin embargo es el hiperlibro-arte el que, por la complejidad de su naturaleza, resulta ser mucho más sustancioso y expansivo en sus posibilidades. Éste se significa por una estructura de la información que posibilita al lector trascender la secuencialidad, ofreciendo inauditas posibilidades de lectura y entrada al documento de carácter virtual. La nomenclatura hiperlibro-arte proviene de la traslación del sistema 
de escritura electrónico o digital -el hipertexto-, al soporte libro, el hiperlibro (Santiago, 2013, p. 35). El hipertexto se define como:

"la organización de una base de información en bloques discretos de contenido llamados nodos (en su mínimo nivel), conectados a través de enlaces cuya selección genera distintas formas de recuperar la información de la base" (Lamarca-Lapuente, 2006).

También la voz hipermedia, que debe su nombre a la suma de los términos hipertexto y multimedia (una red hipertextual incluye no sólo texto sino también otros medios como imágenes, audio, vídeo, etc.), debe considerarse como legítimo origen etimológico y conceptual del vocablo hiperlibro. Si se expande y amplía la morfología de la estructura de escritura hipertextual de datos textuales a datos gráficos, sonoros, animados, audiovisuales o una combinación de parte o de todas estas morfologías de forma concurrente, es decir multimedia, controlados por un lector (interactividad), nos hallamos en un espacio morfológico hipermedia y ello define de manera más rigurosa lo que los parámetros en red nos proveen como consumidores y creadores.

\section{Un hiperlibro-arte es un libro-arte produ- cido exclusivamente mediante estructu- ras tecnológicas digitales interactivas, su- mergiendo tanto a artista como a lector en el particular lenguaje del arte digital}

Por ende, en este trabajo se designa bajo el término hiperlibro-arte aquellos libros-arte producidos exclusivamente mediante estructuras tecnológicas digitales interactivas, sumergiendo tanto a artista como a lector en el particular lenguaje del arte digital. Dichos libros están mayoritariamente formalizados en lo que precisa el anglicismo como screen based books para especificar aquellos libros de concepción y 'consumo' en pantalla (fundamentalmente pantallas multitáctiles ${ }^{2}$ ), cuyo uso del texto se fundamenta en el hipertexto y el del contenido visual en el hipermedia gracias a la interacción (pulsando encima de los mismos o en determinadas zonas sensibles y destacadas, mediante hipervínculos que enlazan de manera automática con otros documentos u otros elementos multimedia).
Antes de pormenorizar sus propiedades y particularidades, se hace imprescindible discernir los términos electrónico y digital. Muy frecuentemente se identifican como congéneres sin literalmente serlo. Lamarca-Lapuente en su tesis doctoral sobre el particular acota sus diferencias y concurrencias al afirmar que:

"Todo documento digital es un documento electrónico pero no ocurre lo mismo al revés, no todo documento electrónico es un documento digital. Un documento electrónico puede ser bien analógico, bien digital. Documentos electrónicos son, por ejemplo, una cinta de casete o una cinta de vídeo, que precisan de un dispositivo electrónico para su lectura, pero no son digitales. Lo que distingue un medio electrónico de un medio digital es, por una parte, la forma en que está codificada la información y, por otra, la necesaria mediación de un ordenador para descodificar esta información. En el caso de un documento digital, la información está codificada en bits, y para leer, visualizar o grabar la información se precisa de un dispositivo que transmita o grabe información codificada en bits. [...] Un documento digital es, pues, aquel que contiene la información codificada en bits" (Lamarca-Lapuente, 2006).

De manera que los documentos electrónicos pueden ser analógicos (en soportes magnéticos: cinta de casete, vídeo, mini dv, disquete, disco zip, etc.) y digitales (en soportes ópticos: cd, cd-rom, dvd, blue-ray disc, etc.).

Y citando nuevamente a Lamarca-Lafuente cabe también matizar que:

"[...] un documento hipertextual es un tipo de documento digital. No todos los documentos digitales son necesariamente hipertextuales, aunque todos los documentos hipertextuales son digitales. No es posible la hipertextualidad sin la tecnología informática y digital" (Lamarca-Lapuente, 2006).

Es por tanto esta cualidad estructural de navegación digital inherente al hiperlibro-arte la que lo distingue del e-libro-arte:

"la micronavegación (en el interior del hiperdocumento), la macronavegación (la navegación entre distintos documentos), las diferentes formas de interactividad, etc." (Codina, 2003, p. 142)
A la luz de lo expuesto y pese a la riqueza de matices de cada uno de ellos, el e-libro-arte responde a una clasificación fundamentada en la naturaleza del soporte (cd-rom, disco duro, iPad, iPod, tarjeta de memoria, teléfono móvil, etc.) y el hiperlibro-arte responde a una clasificación fundamentada en el tipo de estructura de la información (una red de nodos de información interconectados por enlaces: html, xml, sgml, etc.).

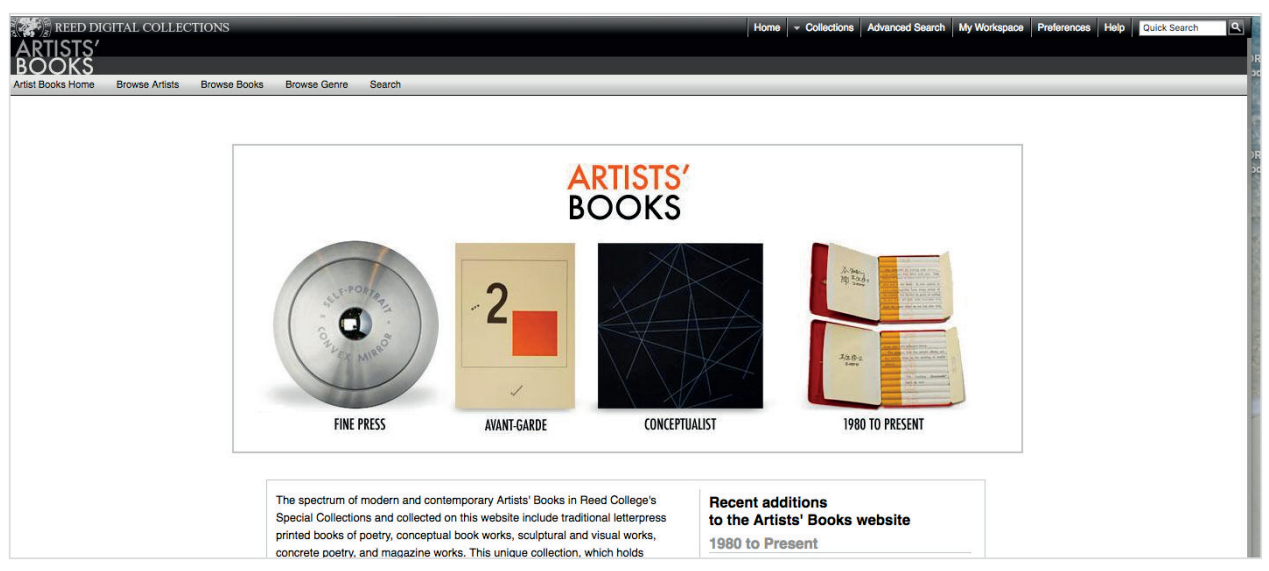

http://cdm.reed.edu/cdm4/artbooks 
"el término hiperdocumento proviene de la contracción de 'documento hipertextual' [...] un hiperdocumento es un documento digital cuyos componentes están organizados en forma hipertextual. [...], un documento digital organizado de forma que sea navegable y que se pueda leer de forma no necesariamente secuencial" (Codina, 2003, pp. 143-144).

Tras definir y conceptualizar el e-libro-arte y el hiperlibro-arte, así como establecer los parámetros de alguna terminología vinculada, conviene ahora tratar sus especificidades.

\section{E-libro-arte digital versus e-libro-arte digitalizado}

Recordemos que se puede distinguir:

- e-libros-arte genuinamente impresos que han sido digitalizados y que opcionalmente pueden volver a imprimirse, y

- e-libros-arte creados digitalmente para poder ser impresos o no.

En los primeros la digitalización ha permitido diseminar este tipo de obras enteramente $-y$ no solamente algunas de las páginas de su totalidad-, sin poner en riesgo su integridad física. De esta forma tenemos la fortuna de ver obras que durante décadas sólo han sido accesibles en bibliotecas especializadas de museos o en colecciones especiales o privadas, con una posibilidad de consulta muy restringida. Actualmente la tecnología posibilita la libre visualización de libros-arte antológicos de Ed Ruscha, Sol LeWitt, Filippo Tomasso Marinetti, El Lissitzky, Sonia Delaunay, David Hockney, Kiki Smith...,

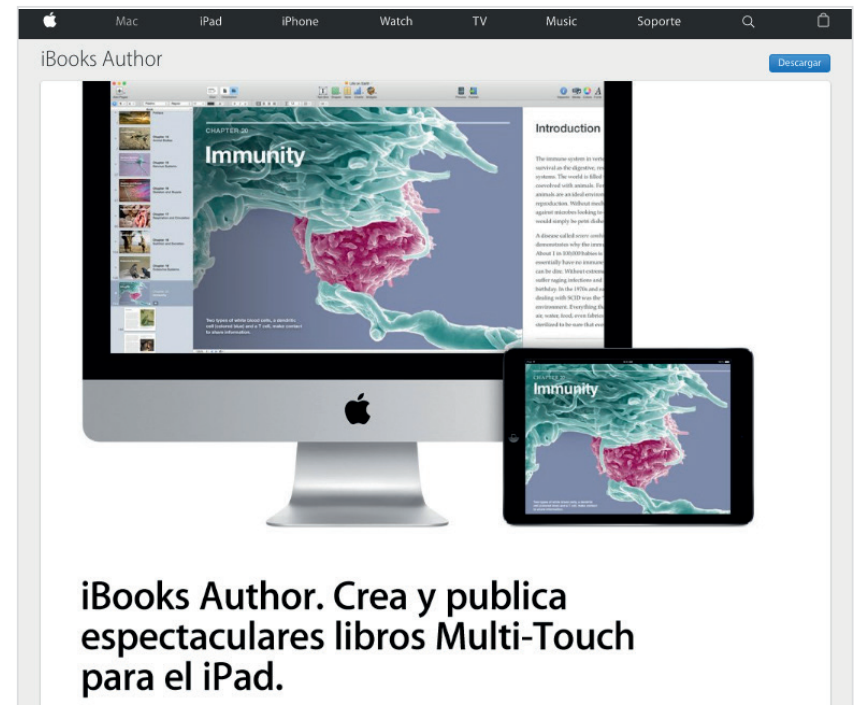

http://www.apple.com/es/ibooks-author
Radostaw Nowakomsi
LIBERLANDIA

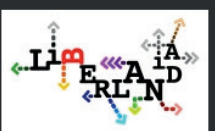

Oto moje parístwo. Państwo o ustroju hipertekstowym. W nieustannej budowie. W niekończącej się przebudowie. Ksiqzika zaczynajaca się w srodku i rozchodzaca na wszystkie strony. Woina ksiqzika dila wolnych czytelnikbow. Kraj, w którym pobyt prawie nic nie kosztuje, ledwie tyle co stracony czas niepotrzebnego.

Radostaw Nowakowsk
LIBERLAND

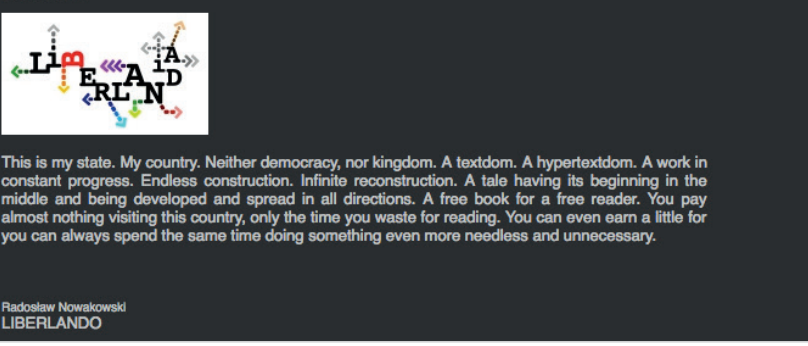

Radoslaw Nowakowsk
LIBERLANDO

http://www.liberatorium.com/liberlandia.html

como la Reed College Digital Collection del Reed College (Portland, Oregon, EUA) que integra más de 80.000 imágenes de obras de arte, mapas y documentos artísticos además de libros-arte. Por otra parte, en caso de ser los propios artistas los que digitalizan sus libros-arte y los exhiben en internet aumentan las posibilidades de autopromoción y oportunidades de distribución y/o venta de sus libros-arte físicos. Así lo hacen artistas como Angela Lorenz, Angie Walle, Radoslaw Nowakowski o Sandra March entre muchos otros.

http://cdm.reed.edu/cdm4/artbooks

http://www.angelalorenzartistsbooks.com

http://angiewaller.com

http://www.liberatorium.com/liberlandia.html

http://www.sandramarch.com

Se pueden distinguir e-libros-arte originalmente impresos que han sido digitalizados y ocasionalmente pueden imprimirse nuevamente y e-libros-arte digitales creados para poder ser impresos

En los segundos, es decir, los e-libros-arte creados digitalmente con la finalidad de ser impresos, los medios de creación en la autoedición y distribución que la era digital nos brinda son inagotables y con ello aumenta lo que representa su gran potencial.

\subsection{Medios de creación de e-libros-arte}

La tecnología digital e internet facilitan una amplia gama de instrumentos y medios para autoeditar. La autoedición se iza no como una banalidad sino como una libertad, ya que en vez de depender de una agencia o industria externa, el artista toma el control absoluto de su propio proyecto. Haciendo un repaso a la oferta, podemos destacar una serie de programas para ello:

- Apple cuenta con una aplicación libre para ordenadores 
Mac, iBook Autor, un software de fácil manipulación para configurar libros multi-táctiles para iPad que cuenta además con un repositorio digital para venderlos o comprarlos, el iBooks Author de Mac App Store.

http://www.apple.com/es/ ibooks-author

- Adobe Indesign es otro software de uso extendido para editar cualquier tipo de material y dejarlo preparado para su publicación, además de permitir editar para su visualización en tabletas y ordenadores.

- Turning The Pages es una empresa pionera en la creación de software para la realización de facsímiles digitales de libros 'raros' en 3-dimensiones, libros en los que las páginas se pueden 'tocar y girar', aproximarse y alejarse con zoom, leerlos o escucharlos, etc. Y en colaboración con ArmadiIlo Systems pone a disposición del cliente la posibilidad de crear sus propias aplicaciones.

http://ttp.onlineculture.co.uk

Los elementos específicos de la esencia del libro-arte son las particularidades y posibilidades de manipular la secuencia, el texto y la forma

\subsection{Medios de distribución de e-libros-arte}

Algunos proyectos editoriales alternativos disponibles en internet ofrecen a los artistas sus plataformas para publicar sus obras o proyectos artísticos; tal es el caso de Bside Books dedicada específicamente a las ediciones limitadas, o CrossMedia Publishing especializada en transformar documentos bidimensionales de alta resolución en proyectos en 3D. Sin olvidar las renombradas Lulu y Blurb, ambas promotoras principales de la tecnología de impresión editorial print-ondemand o publicación bajo demanda (PoD) en el que las copias del libro se van realizando a medida que se solicitan. http://www.bsidebooks.com

http://www.webproof.com/features/features-publish.html http://www.lulu.com

http://www.blurb.com

Este panorama expande las posibilidades de aunar y combinar en proyectos colaborativos a artista/s, diseñador, editor e imprenta. Con tal fin han surgido múltiples propuestas culturales como The Folio Club en Barcelona, o la italo-británica Digicult Editions.

http://www.thefolioclub.com

http://www.lulu.com/spotlight/digiculteditions

No obstante, en todo e-libro-arte el proceso de producción debiera considerarse en segundo orden de importancia para priorizar la idea y el concepto que lo distingue. De esta manera la accesibilidad, y por ende, la democratización de los medios de creación y distribución que permite la era digital, posibilitan un futuro lleno de recursos para los libros-arte. $Y$ es así como estos medios deben ser considerados, vistos, adoptados y celebrados en pro de la formalización y la materialización del e-libro-arte, independientemente de las consideraciones de una, ya no tan emergente, estética digital exclusiva y/o excluyente de estos medios computerizados.

\section{El hiperlibro-arte}

Antes se concretó una definición, pero, ¿qué elementos son los que constituyen su identidad? Al igual que ocurre con el análisis de los componentes que configuran el libro-arte para que puedan ser considerados como tal, y no como otra disciplina artística, son las particularidades y posibilidades de manipulación de la secuencia, el texto y la forma, los elementos específicos de la esencia del libro-arte (CrespoMartín, 2012, p. 2).

\section{El hiperlibro-arte es un libro-arte produ- cido exclusivamente mediante estructu- ras tecnológicas digitales interactivas}

Aunque el tratamiento de estos tres ingredientes en los hiperlibros-arte puede ser similar y/o simular al más tradicional -o el que nos resulta más familiar- de los libros-arte, se examinarán bajo postulados y propuestas de arte digital por su vinculación y estrecho parentesco con sus propios principios constitutivos.

\subsection{Secuencia multilineal y multisecuencial del hi- perlibro-arte}

La secuencia es probablemente lo que determina la primigenia clasificación de cualquier libro-arte, es decir, las diferentes maneras de presentar la sensación de leer, la temporización establecida, el ritmo de lectura o las demostraciones de una cadencia métrica. 


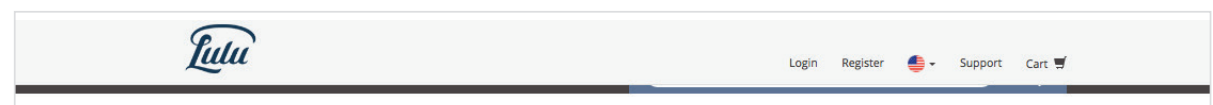

Create, publish and sell your book for free.

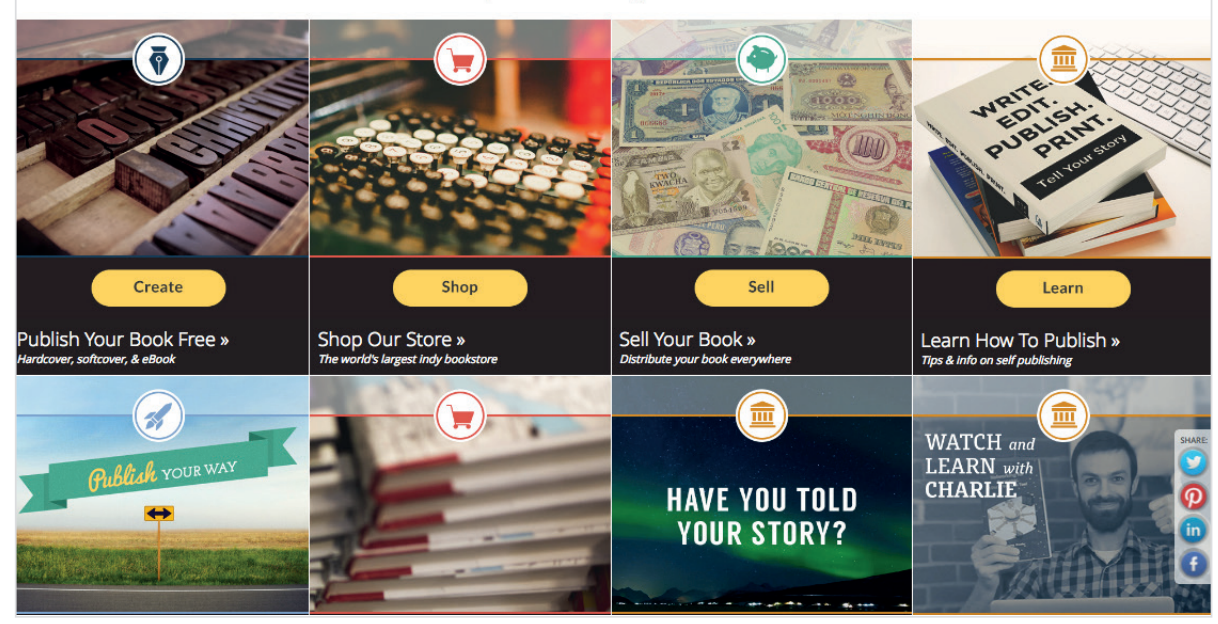

http://www.lulu.com

Gracias a las propiedades del hipertexto -como ingrediente intrínseco a la escritura digital-se puede determinar que en los hiperlibros-arte la secuencia es polimórfica, aleatoria, no lineal, o mejor dicho, multilineal y consecuentemente multisecuencial, lo que no significa no narrativa.

El hiperlibro abandona completamente el imperativo lineal favoreciendo una lectura y estructura multidireccional, de multitud de narraciones alternativas y azarosas. Esto no supone que en la lectura hipermedia reine la confusión y se dé el caos -a menos que esto sea intencionado- ya que los principales contenidos son accesibles en todo momento desde un índice o indexador de menú que nos remite al esqueleto estructural siempre que lo deseemos.

¿Cómo se deben catalogar, compilar, archivar y conservar? ¿Debiéramos desprendernos de este espíritu conservador testimonial cuando se trata de arte electrónico y/o en la Red...?

El creador de hiperlibros-arte se encuentra ahora considerando baremos de lectura que escapan de la lectura lineal y menos aún fija, consecutiva o estable. La obra ha de contemplar un horizonte en el que la ordenación secuencial de los contenidos nunca va a ser la misma, en el que cada vez que el lector-espectador lea-vea la pieza, este acto va a ser diferente y en el que cada lector-espectador actuará e interactuará de manera diferente con el libro. En lugar de un orden sintáctico -textual prescrito-, surge un orden asociativo que únicamente se establece durante y a través del acto de leer. Cabe aquí señalar el intencionado uso del término "lector-espectador" ya que conlleva el rol dual que éste debe asumir al negociar con las funciones escripto-visuales de la misma. Obviamente esto nos remite a un lector-espectador participativo. La secuencia pasa ahora a ser comandada enteramente por la audiencia que interactúa en y con el libro. Desde esta perspectiva, también el artista metamorfosea su rol de manera que pasa a producir y poner a disposición una estructura de contenidos generados mediante la interactividad del lector-espectador en cada una de las lecturas o visionados del libro. Expresado en palabras de Espósito (2003), el espectador

"tiene el potencial de hacer el contenido del libro procesable (factible), no simplemente legible".

Todo ello deviene en un espectador que se convierte en creador análogo, o en coartista de la obra. Esta asignación participativa al lector-espectador es quizás la característica más destacable de los libros-arte digitales. El lector transita y se mueve por la obra interactuando con ella mediante la manipulación de la paginación, los saltos y giros virtuales, tocando, eludiendo o retomando contenidos... Sin embargo, voces autorizadas en este campo han argumentado que esta interrelación dinámica e interactiva entre el lector y el libro se da también en la secuencia tradicional de los libros en forma de códice con estructuras secuenciales también tradicionales:

"Construimos la obra a través de nuestra interacción con ella, no 'recibimos' un libro como estructura formal"

(Drucker, 2003).

Sirva de referencia la obra de Jason Nelson, un artista alentado por experimentar y proyectar espacios de colaboración e intercambio con el espectador. Desde nuestro punto de vista, obras como Birds still warm from flying (2015) confieren un entendimiento muy versado de los medios productivos para dotar y conceder al lector-espectador plenos atributos creativos y consagrar la secuencia multilineal/multisecuencial a su propia elección, gusto, antojo y criterio. http://www.secrettechnology.com/ausco/poecubic2.htm/

\subsection{Hipertexto y escritura visual del hiperlibro-arte}

Vannvear Bush fue el ideólogo del hipertexto en 1945, aunque el término fue acuñado por Theodor Nelson diez años más tarde para referirse al texto presentado en cualquier tipo de dispositivo electrónico interconectado por hipervínculos a otro texto, y normalmente activado por un clic de ratón, presionando una tecla o tocando la pantalla (Nelson, 1983) -el mismo Nelson introdujo el término hipermedia, lo cual confirma la consonancia entre hipertexto e hipermedia con el hiperlibro-.

El hipertexto se basa en una estructura arbórea que favorece saltar de una unidad textual a otra a partir de unas partículas vinculadas e interactivas. Todo ello se muestra en la pantalla como una superficie de discontinuidades temporales, dislocaciones espaciales y rupturas discursivas. Esto 


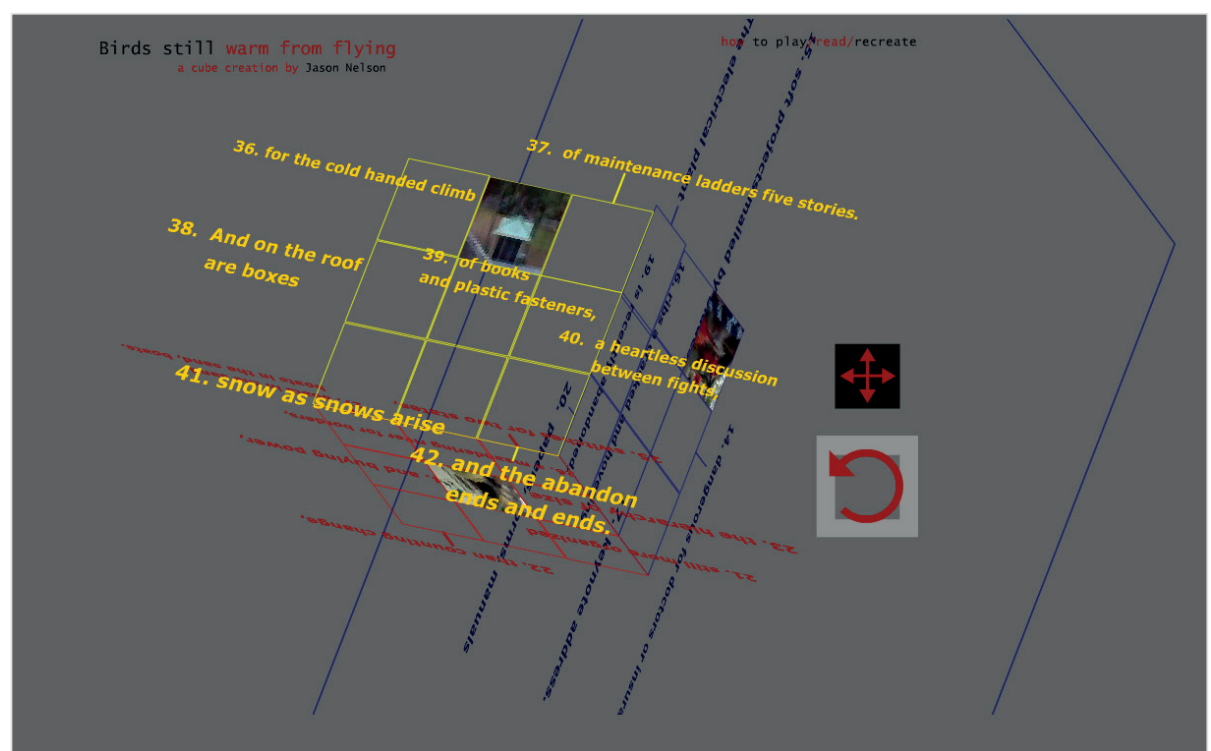

http://www.secrettechnology.com/ausco/poecubic2.html

se parece mucho a los mecanismos procesuales del pensamiento humano que no responden a un formato lineal, sino que se articulan por búsquedas relacionadas de información (Viola, 1988, p. 71). En esta forma narrativa se da una textualidad líquida y fluida. Sin embargo, la linealidad textual de la página impresa siempre ha interpelado esta necesidad no secuencial del pensamiento humano, y agentes intertextuales como las citas bibliográficas, llamadas o aclaraciones, notas a pie, etc., posibilitan introducir metatexto dentro de un libro. En el campo del arte, estas tentativas textuales asociativas tienen claros precedentes en obras antológicas de la literatura universal como Un coup de dés (1897) del poeta simbolista francés Stéphane Mallarmé, los caligramas (1918) de Guillaume Apollinaire o los poetas concretos brasileños de los años 50..., entre otros.

En el contexto de los hiperlibros-arte, si permutamos estas unidades textuales por imágenes que estén interconectadas podemos alegar funciones textuales de la imagen y funciones visuales del texto. $\mathrm{O}$ incluso podemos hablar de una literatura o de una escritura visual (Klanten et al., 2013).

Esta concepción hipertextual e hipermedial de la obra es notoria en la producción del artista portugués Rui Torres. Su obra ostenta portentosamente la creación de nuevas formas dialógicas entre la expresión artística (texto-visual) y la comunicación; y los instrumentos tecnológicos. Si algo puede destacarse en cada una de sus piezas es su interés por interrogar la versatilidad creativa de la poesía experimental, como lo demuestra su obra Amor de Clarice (v. 2) (2008). http://telepoesis.net/amorclarice/v2/amor_index.html

\subsection{Formas y formatos del hiperlibro-arte}

En los libros-arte se entiende por forma la estructura o sistema organizado para servir a los propósitos o intenciones conceptuales del artista y su libro (Crespo-Martín, 2012, pp. 14-15). La propiedad relevante en cuanto a forma en los hiperlibros-arte reside en que son online y/o screen based -en pantalla- en cualquier tipo de dispositivo o periférico electrónico concebido para su visualización. En una cotidianidad invadida por todos ellos pareciera que una de sus ventajas más remarcables es su accesibilidad. Uno de los debates más candentes y controvertidos se centra en el cuestionamiento de si la tradicional forma códice ha sido superada por la introducción de las estructuras electrónicas. Y una vez más, las investigaciones de Johanna Drucker

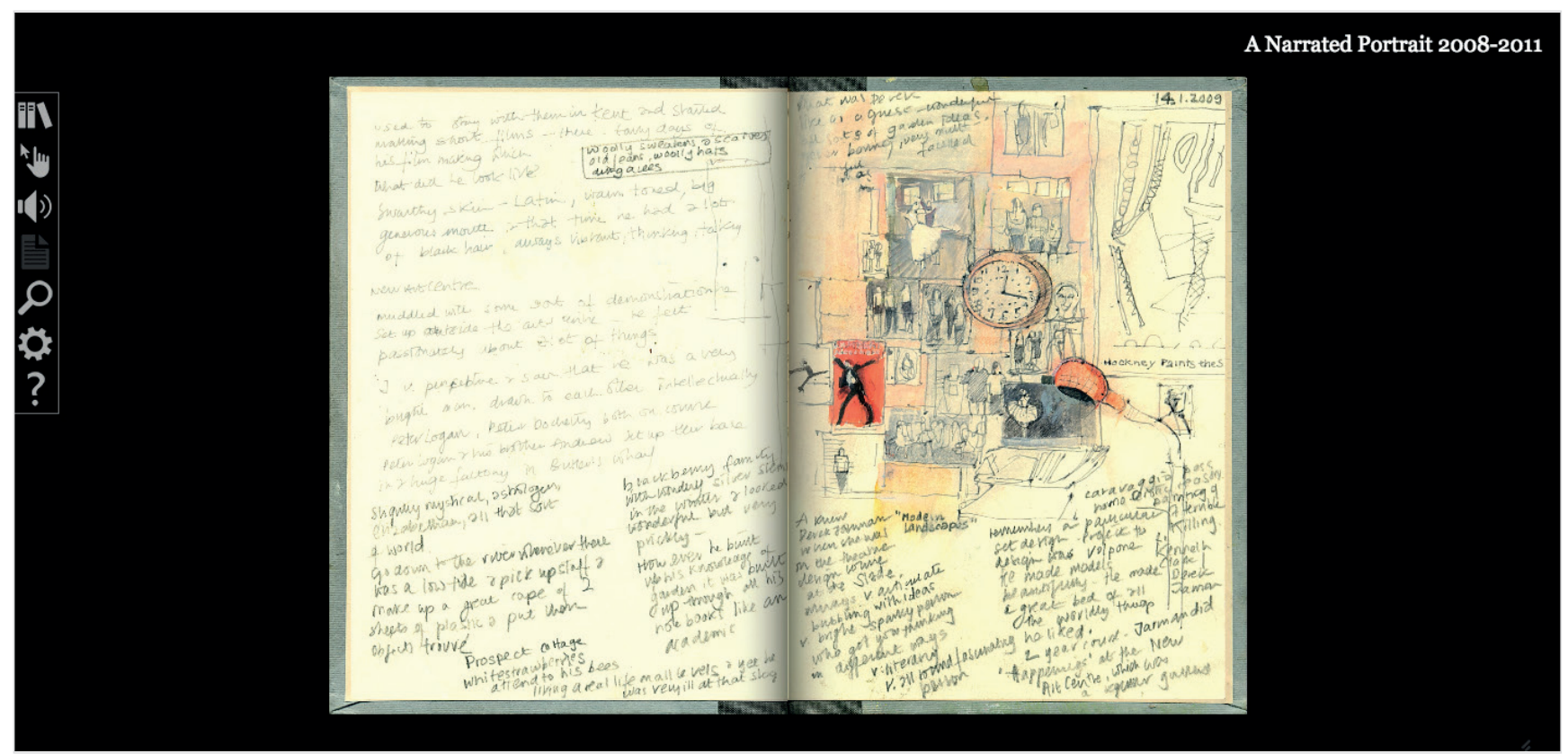

http://eileenhogan.onlineculture.co.uk/ttp 
(2003) son un punto de referencia en esta materia cuando expone sus similitudes, diferencias e incluso defiende la superioridad del tradicional códice, además de la diversidad de formas que puede adoptar el libro con estructuras popup, libros caja, formas rollo, etc.

Lo que sí se puede afirmar es que el medio digital permite acoger cualidades materiales en su forma que le son exclusivas, como enlaces en vivo y en tiempo real o la actualización constante de la información. Esta es probablemente la función más distintiva e innovadora que poseen los espacios electrónicos junto con novedosas percepciones visuales, acústicas y hápticas (táctiles), es decir, todo lo que abarca la realidad virtual. Y nos referimos a novedosas en su acepción de distintas por su correlación con el cuerpo, sintetizado en la realidad virtual, ya que percepciones visuales, acústicas y hápticas se dan igualmente en las formas tradicionales del libro-arte.

Las formas y formatos digitales incrementan aún más sus posibilidades si nos sumergimos en la hibridación de medios, explotando el potencial de combinar pantalla y papel, instalación y escultura..., y así encontramos a muchos artistas trabajando sus libros-arte en verdaderas intersecciones disciplinarias. Desde esta perspectiva multimedial la obra $A$ narrated portrait 2008-2011 (2013) de Eileen Hogan asume altas cotas de mestizaje y sincretismo disciplinar. Es una obra digital interactiva screen-based que incluye dibujo, pintura, grabación de voz y video.

http://eileenhogan.onlineculture.co.uk/ttp

\section{Reflexiones colaterales}

Ante esta realidad de los libros-arte en el contexto digital se otean disentimientos no contemplados hasta ahora. Conceptos tan arraigados como la distinción de roles entre artista y espectador, autoría, unicidad, original versus múltiple, seriación y edición, etc., merecen ahora cuanto menos una reflexión.

Nos hallamos ante un lector-espectador con un cometido más activo y participativo en el acto creativo del libro convirtiéndose en productor (Bishop, 2006), coautor o coartista del mismo; y un artista que deviene generador de contenidos.

Debiéramos pues sopesar el tándem creador/artista-lector/ espectador como algo compartido, difuminando el propio concepto de autoría: ¿nos enfrentamos a una autoría compartida? Con ello se abre un frente de debate inédito, aquel que concierne a la propiedad y a la propiedad intelectual, especialmente si asumimos la dudosa premisa de que la autoría corresponde únicamente al ideólogo de la propuesta a merced de que nadie pudiera darle 'vida'. Mihai Nadin asevera al respecto:

"El medio digital es de réplica instantánea y perfecta fidelidad; por lo tanto, la noción de original, el aura de originalidad, y la atracción de la propiedad tendrán que someterse a reinterpretación y cambio. Nuestra visión de la relación artista-público cambia así como la diferencia entre artista y público desaparece gradualmente" (Nadin, 1989, p. 46).

Las afirmaciones de Nadin nos llevan irremediablemente a la confrontación original versus múltiple en la obra digi- tal. Quizá hemos de repensar el significado tradicional del concepto de "originalidad", entendido éste en su acepción de "unicidad", "autenticidad", "singularidad" u "origen". $Y$ es que todos los libros-arte digitales son originales, todos leemos, interactuamos y "poseemos" la obra original sin que su multiplicidad vaya en detrimento de la obra ni cuantitativa ni cualitativamente. Más taxativo es Nilo Casares cuando afirma que "no existe diferencia entre original y copia porque no hay tal copia" (Casares, 2009, p. 16). Aquel aspecto aurático ${ }^{3}$ conferido a la obra de arte única que le ha ido acompañando a lo largo de toda la historia del arte, se disocia ahora en las propuestas artísticas digitales para dar advenimiento a una obra original idéntica y múltiple, de múltiples originales, todas ellas son originales, son obras multi-originales (Mínguez-García, 2012, pp. 71-87). Bajo este efecto dominó de conceptos vinculados, también cae en desgracia el credo de una disciplina artística seriable sometida a una edición.

El hecho de que muchos de estos libros-arte se encuentren en la nube, comporta la posibilidad de cambiar, o estar cambiando, o actualizándose constantemente; eventuales redireccionamientos, cambios de dominio, retrocompatibilidad de software informático, etc. Estas características inauguran otros espacios de incertidumbre que merecen igualmente una reflexión: cuestiones como ¿cómo se deben catalogar, compilar, archivar y conservar? ¿Debiéramos desprendernos de este espíritu conservador testimonial cuando se trata de arte electrónico y/o en la Red...?

Emulando situaciones de desconcierto similares durante el siglo XX -el movimiento Dadaísta, el arte conceptual, la performance...- entendemos que ahora, como entonces, la tendencia inclusiva imperará hacia un eclecticismo de producción, percepción y perspectiva.

\section{Notas}

1. Propedéutica es el conjunto de saberes necesarios para preparar el estudio de una materia, ciencia o disciplina.

2. Las pantallas multitáctiles reconocen simultáneamente varios puntos de contacto.

3. "Ello le da pie para dividir la obra de arte en dos tipos: la 'aurática', es decir, la original, única, enlazada al contexto de su tradición y la 'profana', caracterizada por ser repetible, reactualizable y carente de valor histórico, geográfico o autoral. Mientras que la primera, posee cierta carga cuasi sagrada, la segunda se realiza plenamente al ser exhibida pues su función es únicamente la de crear una experiencia estética de la belleza" (Walter Benjamín, 2003. La obra de arte en la época de su reproductibilidad técnica. México: Ítaca, pp. 42-57).

\section{Bibliografía}

Bishop, Claire (ed.) (2006). Participation. London: Whitechapel/Cambridge. MIT Press. ISBN: 97802622464 http://academicworks.cuny.edu/cgi/viewcontent. cgi? article $=1096 \&$ context $=g c \_$pubs

Bodman, Sarah; Sowden, Tom (2010). "A manifesto for the book". En: Bodman, Sarah; Sowden, Tom (eds.). A manifesto for the book. Bristol: Impact Press, pp. 5-10. ISBN: 978 1906501044 
http://www.bookarts.uwe.ac.uk/publications/manifestofor-the-book.html

Casares, Nilo (2009). Del net.art al web-art 2.0. Valencia: Diputación de Valencia, Institució Alfons el Magnànim. ISBN: 9788478225491

http://es.scribd.com/doc/22247653/del-net-art-al-web-art-2-0

Codina, Lluís (2003). "Hiperdocumentos: composición, estructura y evaluación”. En: Díaz-Noci, Javier; Salaverría, Ramón (coord.). Manual de redacción ciberperiodística. Barcelona: Editorial Ariel, pp. 141-168. ISBN: 978 8434412972

https://www.academia.edu/16377738/Hiperdocumentos_ composici\%C3\%B3n_estructura_y_evaluación

Crespo-Martín, Bibiana (2010). “El libro-arte. Clasificación y análisis de la terminología desarrollada alrededor del libroarte". Arte, individuo y sociedad, v. 22, n. 1, pp. 9-26.

http://revistas.ucm.es/index.php/ARIS/article/view/ ARIS1010110009A/5739

Crespo-Martín, Bibiana (2012). "El libro-arte/libro de artista: tipologías secuenciales, narrativas y estructuras". Anales de documentación, v. 15, n. 1, pp. 1-25.

https://doi.org/10.6018/analesdoc.15.1.125591

Drucker, Johanna (2003). "The virtual codex from page to espace". En: History of the book seminar, Syracuse University. http://www.philobiblon.com/drucker

Esposito, Joseph J. (2003). "The processed book". First Monday, v. 8, n. 3.

https://doi.org/10.5210/fm.v8i3.1038

García-Marco, Francisco-Javier (2008). “El libro electrónico y digital en la ecología informacional: avances y retos". EI profesional de la información, v. 17, n. 4, pp. 373-389.

https://doi.org/10.3145/epi.2008.jul.02

Klanten, Robert; Losowsky, Andrew; Hübner, Matthias; Ehmann, Sven (2013). Fully booked: Ink on paper. design \& concepts for new publications. Berlin: Gestalten. ISBN: 978 3899552096

Lamarca-Lapuente, María-Jesús (2006, actualizada 2013). Hipertexto, el nuevo concepto de documento en la cultura de la imagen. Tesis doctoral. Universidad Complutense de Madrid.

http://www.hipertexto.info

Mínguez-García, Hortensia (2012). "La gráfica múltiple en la cultura de la copia. Una aproximación fenomenológica". En: Soler, Ana (coord.). Originalidad en la cultura de la copia. Encuentros de interacción gráfica. Pontevedra: Servicio de Publicaciones de la Universidad de Vigo, pp. 69-86. ISBN: 9788481585827

http://grupodx5.webs.uvigo.es/encuentros-de-intereacciongrafica.html

Nadin, Mihai (1989). "Emergent aesthetics: Aesthetic issues in computer arts". Leonardo. Computer art in context: Siggraph'89 Art show catalog. Supplemental issue, v. 2, pp. 43-38.

https://doi.org/10.2307/1557943

Nelson, Theodor-Holm (1983). Literary machines. Sausalito, California: Mindful Press. ISBN: 0893470627

Nowakowski, Radoslaw (2009). "End of the world". Liberatorium. The book laboratory.

http://www.liberatorium.com

Santiago, José-Andrés (2013). "El hiperlibro, la fractura y el infinito". En: Soler-Baena, Ana (ed.). The print factory II. El espacio del libro. Pontevedra: Gráficas Salnés SL, pp. 32-37, ISBN: 9788415097754

http://grupodx5.webs.uvigo.es/IMG/pdf/The_Print_ Factory_IIsample.pdf

Viola, Bill (1988). "Y aura-t-il copropriété dans l'espace de données?". Communications, v. 48, n. 1, pp. 61-78.

http://www.persee.fr/web/revues/home/prescript/article/ comm_0588-8018_1988_num_48_1_1720

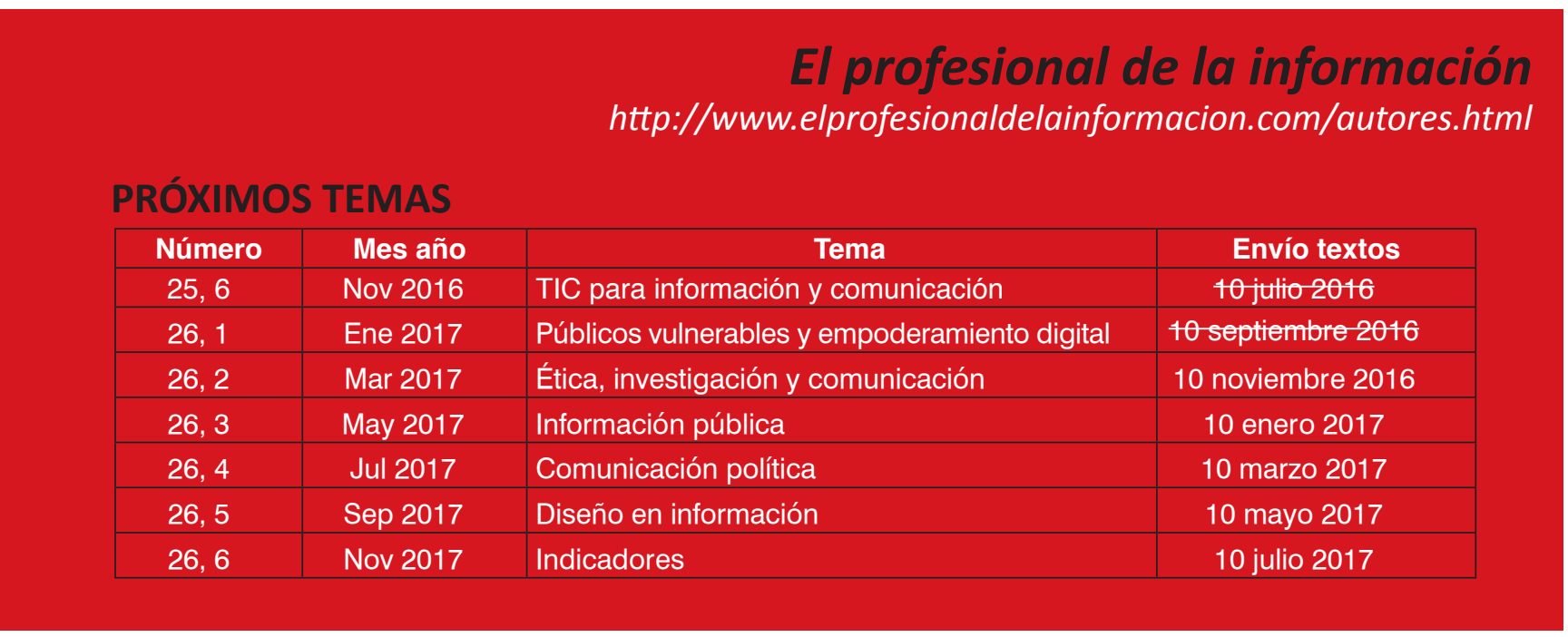

